\title{
EMPRÉSTIMO E TRANSPORTE: NEGOCIAÇÕES DE SENTIDOS NA EDUCAÇÃO MATEMÁTICA DE JOVENS E ADULTOS
}

\author{
BORROWING AND HAULING: NEGOTIATIONS OF MEANINGS \\ IN THE MATHEMATICAL EDUCATION OF YOUTH AND ADULTS \\ MARLUCE ALBRING COUTINHO \\ ELISABETE ZARDO BÚRIGO²
}

\section{RESUMO}

Este texto apresenta e discute um episódio de negociação entre alunas e professora em uma sala de aula de educação de jovens e adultos, durante 0 estudo do algoritmo escolar da multiplicação. 0 episódio é analisado a partir da perspectiva da negociação de significados, conforme proposto por Alan Bishop e Fred Goffree. A discussão travada entre professora e alunas a partir das diferentes concepções de "empréstimo e transporte" traz para o centro do episódio as negociações de sentidos e significados que as interações verbais propiciam entre os sujeitos. A observação participante foi a metodologia adotada para a realização da pesquisa, acompanhada de gravações em áudio das aulas e registros fotográficos dos materiais e das escritas das alunas. 0 estudo do episódio narrado revela que os sujeitos negociam modos de aplicação do algoritmo escolar de multiplicação e indica complexidades na apropriação da matemática escolar pelos jovens e adultos que retornam à escola.

Palavras-chave: Educação de jovens e adultos. Negociações na sala de aula. Educação matemática. Interações verbais. Algoritmo escolar da multiplicação.

\section{ABSTRACT}

This text presents and discusses an episode of negotiation between young and adult students and teacher in a classroom studying the school algorithm of multiplication. The episode is analyzed from the perspective of the negotiation of meanings, as proposed by Alan Bishop and Fred Goffree. The discussion between teacher and students based on the different conceptions of "borrowing and hauling" provides visibility to the negotiations of senses and meanings adjacente to verbal interactions provide between the subjects. Participant observation was the methodology adopted for conducting the research, accompanied by audio recordings of the classes and photographic records of the materials and writings of the students. The study of the narrated episode reveals that the teacher and the students negotiate ways of applying the school multiplication algorithm and indicates complexities in the appropriation of school mathematics by young people and adults.

Keywords: Youth and Adult Education. Negotiations in the classroom. Mathematical Education. Verbal Interactions. School multiplication algorithm.

1 Mestre em Ensino de Matemática pela Universidade Federal do Rio Grande do Sul (UFRGS). Email: marluce.coutinho@gmail.com. ORCID: https://orcid.org/0000-0002-7091-2748.

2 Doutora em Educação pela Universidade de São Paulo (USP). Professora Titular da Universidade Federal do Rio Grande do Sul (UFRGS).

Email: elisabete.burigo@ufrgs.br. ORCID: https://orcid.org/0000-0003-1532-7586 


\section{INTRODUÇÃO}

Conversas, perguntas, respostas, explicações, argumentações, discussão, olhares... Nas salas de aula, professores e alunos convivem e compartilham saberes, em constante interação e negociação.

Os diferentes pontos de vista, de interpretação e a variedade de conhecimentos prévios que professores e alunos trazem para a sala de aula enriquecem as interações que são travadas nesse ambiente. A sala de aula de matemática, ambiente de discussão, perguntas, explicações, orientações, regras e procedimentos, torna-se palco de episódios repletos de negociações de sentidos e significados, sobre a matemática ou sobre o processo de escolarização.

Este artigo trata de um episódio de negociação entre professora e alunas durante o estudo do algoritmo escolar da multiplicação. Nesse episódio, as palavras empréstimo e transporte, frequentemente proferidas em aulas sobre as operações aritméticas básicas da matemática, desencadeiam uma interessante discussão em torno da apropriação dos procedimentos e etapas do algoritmo escolar da multiplicação. Alunas e professora, a partir dos seus conhecimentos prévios e expectativas, nos mostram o quanto uma interação pode ser repleta de negociações.

Olhar, escutar e interpretar episódios de uma aula pode nos dar indícios de como 0 ensino da matemática acontece no cotidiano escolar, e, nesse caso, em uma sala de aula da educação de jovens e adultos. Apresentamos um episódio narrado em dissertação de mestrado acadêmico em Ensino de Matemática, na qual nos propusemos a investigar a dinâmica de uma sala de aula da modalidade educação de jovens e adultos (EJA), noturna, nas totalidades iniciais do Ensino Fundamental, focando as interações verbais em aulas de matemática.

Ao olhar para a sala de aula da EJA, nosso interesse principal era estudar as interações verbais entre os sujeitos para entender o modo como os jovens e adultos veem e se relacionam com a escola e com a matemática escolar; como mobilizam seus conhecimentos prévios durante 0 estudo das operações aritméticas e se realizam conexões com suas experiências do dia-a-dia. Consideramos que esse olhar nos auxilia a identificar como jovens e adultos aprendem e mobilizam seus conhecimentos em relação à matemática e como esses alunos se relacionam com a sala de aula e a escola.

$\mathrm{Na}$ aproximação do tema, nos deparamos com autores que estudam negociações de significados matemáticos. Com base nessa perspectiva, iniciamos a construção de um olhar, ou melhor, de uma escuta para as negociações em sala de aula entre professores e alunos.

Mas, o que é negociar? Ou, o que se negocia em sala de aula?

Entendemos que a negociação em sala de aula acontece porque professores e alunos têm pontos de partida diferentes: negociam a organização da sala de aula, as execuções das atividades e, também negociam sentidos e significados matemáticos. Nas negociações verbais, ao formularem pedidos, interrogações, orientações, limites, os sujeitos também explicitam diferentes pontos de vista sobre a atividade escolar, que em outras situações podem passar despercebidas.

Os textos que tratam das negociações em sala de aula, em geral, referem-se às turmas frequentadas por crianças e adolescentes. Será que os jovens e adultos da EJA negociam com os professores e com os colegas? Ou, o que e como negociam? Essa pergunta nos instigou a pensar sobre como interpretar as interações que acontecem em uma sala de aula da EJA em uma aula de matemática. Propusemo-nos a observar essas interações, os diálogos que compõem a sala de aula de matemática, por meio de uma escuta atenta, a fim de entender um pouco sobre 0 que acontece nesse ambiente complexo e singular que é uma sala de aula. 
Escolhemos assistir e ouvir uma sala de aula da EJA, em uma escola pública, em uma turma de totalidades iniciais - denominação que corresponde aos anos iniciais da escolarização -, com o intuito de observar as interações, mais precisamente as negociações de sentidos e de significados matemáticos travadas naquele ambiente e que ocorrem durante 0 estudo das operações aritméticas básicas da matemática - adição, subtração, multiplicação e divisão. Neste texto, enfocamos as interações verbais entre os sujeitos, professora-alunas, alunas-alunas, em um episódio que narra 0 estudo do algoritmo escolar da multiplicação, buscando identificar as negociações envolvidas e compreender como elas ocorrem nessa turma.

\section{A CONSTRUÇÃO DO OLHAR E DA ESCUTA DAS INTERAÇÕES}

Para subsidiar nosso olhar e nossa escuta das interações na sala de aula da EJA, tomamos como pilares estudos no campo da educação de jovens e adultos, as concepções da comunicação verbal de Bakhtin (1992, 1997) e a perspectiva de negociação de significados de Bishop e Goffree (1986).

Tendo em vista a formação de professores, Bishop e Goffree (1986) abordam as ideias de negociações de significados matemáticos nas salas de aula. Para os autores, professores e alunos negociam e as interações verbais são formas de explicitar e de perceber essas negociações. Eles salientam a maneira singular e pessoal como cada um se relaciona com as ideias matemáticas desenvolvidas em sala de aula, a partir das suas experiências prévias. Os autores apresentam a comunicação como conceito-chave para a construção de um conjunto compartilhado de significados matemáticos. Salientam que, ao olhar para a sala de aula, é fundamental entender que é constituída por pessoas e que elas possuem características individuais singulares naquele grupo. Cada indivíduo tem suas próprias experiências e concepções sobre os outros, construindo suas metas e objetivos a partir do que acontece na sala de aula, inclusive sobre os conteúdos matemáticos. Segundo os autores, os alunos estabelecem conexões entre uma nova ideia matemática, os seus conhecimentos prévios sobre matemática ou outras áreas e conhecimentos sobre situações do mundo real. Os conjuntos de conexões e significados, portanto, variam de aluno para aluno. Professores e alunos, contudo, podem negociar um conjunto compartilhado de significados.

A negociação é geralmente concebida como uma interação guiada por um objetivo; na sala de aula, pode estar relacionada com conceitos matemáticos ou com a organização e dinâmica das atividades. Regras de convivência, método de resolução de uma tarefa, acordos sobre maneiras de responder às questões, são alguns exemplos de negociações que podem ocorrer nas salas de aula. Os autores enfatizam 0 caráter pessoal e singular das estratégias que os alunos desenvolvem para "sobreviver na sala de aula nos contextos de interações efetivadas entre eles" (BISHOP; GOFFREE, 1986, p. 344). ${ }^{3}$

Bishop e Goffree (1986) abordam as ideias de negociações ao olharem para salas de aula de crianças e adolescentes. Os autores apresentam premissas que identificamos serem relevantes para a educação de jovens e adultos, pois consideram os singulares modos de relacionar-se com a matemática escolar. Entendemos que as negociações de sentidos e significados podem ser um caminho para interpretar como os adultos aprendem, focalizando na escuta atenta dos diálogos travados.

No campo da educação de jovens e adultos, observamos que alguns autores trazem para seus textos narrativas de episódios e transcrição de diálogos dos momentos de interação verbal em sala

3 A partir da leitura de Bakhtin $(1992,1997)$ e considerando a abordagem proposta pelo autor sobre o estudo da língua, apoiamo-nos em Vygotsky (1996) para entender a distinção entre sentido e significado. Com isso, consideramos que aquilo que Bishop e Goffree (1986) caracterizam como negociações de significados pode ser caracterizado, em geral, como negociações de sentidos e, eventualmente, como negociações de significados matemáticos. 
de aula (GOMES, 2007; 2013; SANTOS, 2008; FONSECA, 2001). Essa abordagem traz para o leitor a possibilidade de visualizar a cena narrada, acompanhando os diferentes desfechos que uma interação, uma negociação pode ter no contexto da sala de aula. Gomes (2007) reflete sobre a busca de sentido das práticas pedagógicas em uma turma da EJA e sobre negociações de significados. A autora caracteriza que

Negociar significados é experienciar relações; é trabalhar com o poder da palavra, com o jogo intelectual do sentido da palavra; é permitir que a palavra nos transforme e concebê-la como plural e heterogênica; é entender a relação da linguagem com as palavras; é constituir, construir e aceitar formas de pensar e/ou raciocinar diferentes (GOMES, 2007, p. 58).

Para Gomes (2007), o uso da linguagem é a essência da negociação e negociar envolve os indivíduos em um processo de compartilhamento de significados por meio da linguagem. As negociações geralmente envolvem interações verbais, contudo, nesse jogo intelectual, ações, olhares e silêncios podem caracterizar outras formas de negociação.

Entendemos que pesquisar sobre as interações que compõem a sala de aula da EJA envolve entender o lugar, os sujeitos dessas interações e como elas integram o estudo da matemática. Envolve entender que os sujeitos têm histórias diferentes e diferentes concepções sobre a sala de aula, sobre estar nela e sobre a matemática. A partir dessas diferenças, os sujeitos negociam tarefas, procedimentos, rotinas, ideias, saberes.

Fonseca (2007) analisa os aspectos discursivos das interações entre os sujeitos refletindo sobre a significação da matemática que se aprende, considerando a dimensão histórica da enunciação. Com isso, a autora considera que os enunciados são proferidos em uma situação discursiva específica, de ensino-aprendizagem, e que ressoam ecos de outros enunciados.

A escuta das enunciações dos sujeitos na sala de aula pode nos dar indícios sobre seus interesses na escola, suas concepções sobre a modalidade e sobre as relações que estabelecem entre os seus conhecimentos e a matemática escolar. As enunciações constituídas na sala de aula da EJA estão impregnadas de um modo de relacionar-se coletivamente nesse ambiente. Elas são marcadas pelo contexto escolar em que são proferidas, e fazem emergir traços culturais dos sujeitos que as enunciam, dando indícios das relações estabelecidas entre os sujeitos e a instituição social (escola).

Encontramos em Bakhtin $(1992,1997)$ alguns conceitos que nos subsidiaram para uma análise que contemplasse a dimensão social das enunciações constituídas na sala de aula de matemática da EJA. Para 0 autor, as formas de interação verbal estão ligadas às condições concretas em que se realizam. Elas dependem do tipo de relação social estabelecida entre os locutores e constituem-se de acordo com o lugar e o contexto em que são efetivadas; 0 lugar estabelece a(s) forma(s) de interação. Para 0 autor, "a comunicação verbal não poderá jamais ser compreendida e explicada fora desse vínculo com a situação concreta" (BAKHTIN, 1992, p. 124).

Para Bakhtin (1992), a comunicação verbal, entendida como uma cadeia de enunciados concretizados em uma esfera da comunicação, constitui-se de enunciados proferidos por um sujeito a outro. A expressividade de um enunciado é provocada pelo contato da língua com uma realidade concreta; o meio social, a época são alguns dos fatores que "dão o tom" ao enunciado.

Bakhtin (1997) relaciona as esferas das atividades humanas com esferas de comunicação verbal. Uma esfera de comunicação caracteriza-se pelos modos como a língua é utilizada pelos 
integrantes, por meio de enunciados. Cada esfera da comunicação possui enunciados específicos, marcados pelo conteúdo, finalidade e construção composicional de suas especificidades. 0 autor considera que é possível identificar os gêneros do discurso como "tipos relativamente estáveis de enunciados" (1997, p. 279), estabelecidos pelas especificidades das esferas da comunicação verbal.

A relação do locutor com os demais parceiros da comunicação verbal constitui uma das particularidades do enunciado, o que, segundo 0 autor, nos remete a observar que um enunciado possui intenção, tem um intuito-discursivo, um querer-dizer. 0 intuito considera a esfera e os outros participantes da comunicação verbal. Um enunciado toma forma de acordo com o meio em que é proferido, com o estilo que assume a partir da esfera de comunicação em que ocorre, e considerando os outros locutores e outros enunciados proferidos. É um fenômeno complexo que, sendo elo na cadeia da comunicação verbal, deve ser analisado na sua relação com 0 autor e com outros enunciados.

Assim, segundo Bakhtin, o "querer-dizer" do locutor molda-se conforme a situação concreta em que 0 enunciado é proferido, considerando a especificidade de uma esfera de comunicação.

Fonseca (2007) considera que as negociações que acontecem nas salas de aula de adultos realizam-se privilegiadamente nas interações verbais. A autora salienta que os processos de ensino e aprendizagem são uma arena para a negociação de significados matemáticos e que a significação, envolvendo processos cognitivos individuais, é forjada na trama das negociações de sentidos entre aprendizes, professores e materiais disponíveis.

Com essas ideias, olhamos para uma turma enfocando as negociações travadas naquela sala de aula. Observamos que ocorrem negociações de sentidos em torno das práticas escolares, das dinâmicas, dos usos de linguagem e dos sentidos atribuídos à permanência na escola e ao estudo e aprendizagem da matemática escolar.

\section{A PESQUISA E OS SUJEITOS ENVOLVIDOS}

A pesquisa de campo foi realizada em uma turma das totalidades iniciais ${ }^{4} 1$ e 2 , no primeiro semestre de 2018, em uma escola de Ensino Fundamental localizada na região central de Porto Alegre, integrante da rede estadual de ensino do Rio Grande do Sul. A turma, denominada T2, abrangia alunos das duas totalidades de conhecimento e contemplava a etapa de escolarização correspondente ao primeiro, segundo, terceiro, quarto e quinto anos do ensino de crianças e adolescentes.

As interações verbais entre professora e alunos dessa turma realizavam-se predominantemente nos momentos de resoluções dos exercícios propostos ou de explicações de exemplos. Vários momentos de negociações que foram registrados durante a realização da pesquisa, em que a matemática escolar foi o foco principal dos episódios.

Para entender as relações entre os sujeitos e as enunciações produzidas por eles, fez-se necessário o "mergulho" no ambiente em que essas interações são constituídas, em que as enunciações são proferidas, e buscar entender os sentidos dessas interações. A pesquisa foi desenvolvida no ambiente escolar: a escola, seus espaços coletivos e, sobretudo, a sala de aula da turma pesquisada. Adotamos a observação participante como principal metodologia, mas também foram realizadas entrevistas individuais com os participantes, anotações em caderno de campo e gravação em áudio

40 currículo da EJA, no estado do Rio Grande do Sul, é organizado em Totalidades de Conhecimento. Para o Ensino Fundamental são seis totalidades: duas totalidades iniciais e quatro totalidades finais. As totalidades iniciais (1 e 2) correspondem aos cinco anos iniciais do Ensino Fundamental e são desenvolvidas em dois semestres cada um com duração de 300 horas e abordam as áreas de conhecimento de forma globalizada. 
das interações 5 . Para a coleta de dados foram realizados registros em caderno de campo das observações, gravação e transcrição de áudios das aulas e conversações para obter um registro tão fiel quanto possível das interações verbais, e registros fotográficos do quadro branco, cadernos, materiais e de escritas dos sujeitos, mediante consentimento prévio dos participantes. A escola consentiu com a realização da pesquisa e os sujeitos pesquisados assinaram termo de consentimento livre e esclarecido para a coleta dos dados e reprodução para fins acadêmicos.

A turma T2 contava com alunos de diferentes trajetórias prévias de escolarização. Participaram da pesquisa 10 alunos, mas nesse episódio teremos como sujeitos apenas duas alunas e um aluno (além da professora). Eles serão identificados no relato por nomes fictícios, a fim de manter seu anonimato: Antônio (42 anos, trabalhador da construção civil), Alana (16 anos, aluna egressa do ensino de crianças e adolescentes), Rosângela (40 anos, líder comunitária e representante da comunidade nas intermediações com o poder público municipal), e Maria, professora da turma.

0 estudo da Matemática estava presente na maior parte do tempo nessa turma e estava centrado nas quatro operações básicas da aritmética: adição, subtração, multiplicação e divisão. Ao participar do noite-a-noite dessa turma, foi possível acompanhar o estudo das operações, os conceitos e os algoritmos escolares utilizados nessa escola. Nas primeiras semanas de aula foram estudadas as operações e algoritmos relativos à adição e subtração. No mês de abril iniciou-se 0 estudo da operação de multiplicação, com definições e atividades envolvendo a compreensão do significado da operação. Relatamos um episódio ocorrido em uma noite de estudo do algoritmo da multiplicação, em que alunos e professora negociam estratégias de resolução, formatos de escrita e regras de aplicação do algoritmo escolar. Durante a leitura do episódio, é possível acompanhar as negociações realizadas entre os sujeitos.

Empréstimo e transporte: as negociações envolvendo o uso do algoritmo escolar de multiplicação

Na primeira aula sobre a multiplicação, a professora iniciou definindo a operação como a soma sucessiva de fatores iguais e entregou a cada aluno uma folha impressa com a tabuada de multiplicação, contendo os resultados das operações entre números de um algarismo (1 ao 9) separados em colunas para ser consultada durante a realização das atividades propostas. Os primeiros exercícios de aplicação do algoritmo eram de cálculos com números de somente um algarismo, por exemplo, $2 \times 5$.

Figura 1 - Exemplos das tabuadas dos números 1 e 2 que constavam nas folhas distribuídas.

$$
\begin{array}{|l|l}
\hline 1 \times 1=1 & 1 \times 2=2 \\
2 \times 1=2 & \\
3 \times 1=3 & 2 \times 2=4 \\
4 \times 1=4 & 3 \times 2=6 \\
5 \times 1=5 & 4 \times 2=8 \\
6 \times 1=6 & 5 \times 2=10 \\
7 \times 1=7 & 6 \times 2=12 \\
8 \times 1=8 & \\
9 \times 1=9 & 7 \times 2=14 \\
10 \times 1=10 & 8 \times 2=16 \\
9 \times 2=18 \\
10 \times 2=20
\end{array}
$$

Fonte: Adaptação criada pela pesquisadora para ilustrar a situação narrada. 5 Os objetivos da pesquisa foram previamente informados a todos os participantes e, ao aceitarem participar da pesquisa, foi recolhida a
assinatura em termo de consentimento. 
Como estratégia inicial de resolução dos exercícios, as alunas Rosângela e Patrícia contavam desenhos de objetos (riscos ou bolinhas) para a obtenção dos resultados e Alana realizava somas sucessivas de um dos fatores, ambas estratégias explicadas nas primeiras aulas.

Na noite desse episódio, terceira aula do estudo dessa operação, o foco das atividades foi a aplicação do algoritmo escolar de multiplicação, nos casos em que um ou mais fatores têm mais de um algarismo. Um dos exercícios solicitados foi $42 \times 3$, exercício escrito no quadro para resolução por meio do algoritmo. Rosângela questiona se "dá pra fazer quarenta e dois vezes três?". Até aquele momento, apenas um exercício de multiplicação com números de dois algarismos havia sido abordado, para a explicação do algoritmo, e o número 42 causa estranheza a Rosângela. A professora explica 0 cálculo mostrando a separação das ordens das dezenas e das unidades, informando que o resultado "pula" para a próxima ordem, das centenas, no caso, conforme observado na Figura 2.

Figura 2 - Registros no quadro do cálculo efetuado pela professora com as indicações das ordens de grandeza dos números e, abaixo, a indicação do número 12 composto por dezena e unidades.

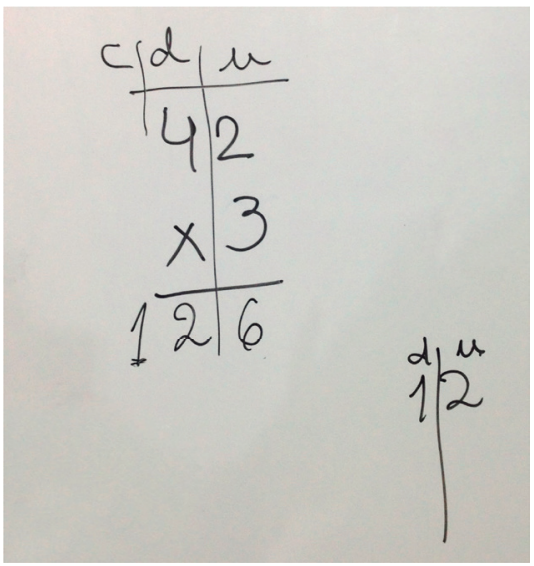

Fonte: Acervo da pesquisadora.

Professora: Mesma situação: unidade e dezena [fazendo riscos para separar as or-

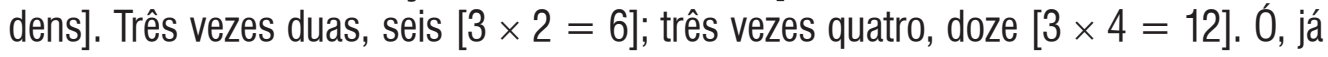
deu lá na casa da centena.

Rosângela: Aah, tem que pedir 0 um.

Professora: Pode ir até o milhar, ou milhão...

Rosângela: Mas quando for número alto tem que pedir para centena, dezena?

Professora: Não. Aqui tu não tens que pedir nada emprestado. Não tem que pedir, nós só estamos multiplicando. Três vezes dois deu seis, não foi nada para lá [referindo-se à conversão de unidades em dezenas] porque seis é a unidade. Agora três vezes quatro dá doze, que é duas unidades e uma dezena. Só que aqui deu na casa das dezenas, então ele fica 0 dois aqui [dezena] e 0 um vira cem, vai pra casa da centena.

Rosângela: Então essas de vezes não tem nada pra pedir emprestado para ninguém. Professora: Não, pedir emprestado não.

Rosângela: Só de mais e de menos?

Professora: Só tem que quando tiver... se por acaso aqui...

[Começa a explicação do outro exemplo, $132 \times 4$ ] 
Rosângela considera o número 42, com dois algarismos, "um número alto", e talvez nesse caso "tem que pedir para centena ou dezena". No estudo da subtração, em alguns casos, uma das etapas orientadas pela professora para o uso do algoritmo é o "empréstimo", "pedir emprestado", que consiste em decompor uma centena em dezenas, ou uma dezena em unidades, no primeiro termo, para viabilizar a subtração. 0 registro dessa etapa é feito com a escrita do algarismo "1" à esquerda do algarismo das dezenas ou unidades sobre as quais se pretende aplicar a subtração. Rosângela associa a escrita do algarismo 1, das centenas, no resultado "126", ao algoritmo usado na subtração e utiliza a mesma expressão da professora para caracterizar o procedimento. Ao falar que "aqui tu não tens que pedir nada emprestado", a professora explicita o que não deve ser feito no algoritmo da multiplicação: não precisa pedir emprestado. A palavra "aqui" na frase da professora, traz a ideia de que nesse cálculo, utilizando o algoritmo da multiplicação, não ocorre a etapa de empréstimo, enfatizando que a palavra "empréstimo" não caracteriza um procedimento do algoritmo da multiplicação. A professora não aborda a diferença entre o procedimento usado na multiplicação e o "empréstimo", e Rosângela afirma que "essas de vezes não têm nada pra pedir emprestado para ninguém", numa tentativa de confirmar o procedimento a ser adotado.

Um outro exemplo é utilizado pela professora no intuito de explicitar o procedimento de conversão entre diferentes ordens de grandeza, explicitando todas as etapas do algoritmo: $132 \times 4$. 0 resultado 528 parece não ficar claro para Rosângela, ela tem uma expressão facial de dúvida. Quando a professora escreve no quadro 0 resultado da multiplicação $3 \times 4$, ela murmura que "três vezes quatro é doze" mas a professora escreve no resultado final apenas 0 algarismo 2 e registra 0 algarismo 1 com um tamanho menor, acima do algarismo "1" do fator 132.

Para esclarecer que nesse algoritmo não há "empréstimo", a professora salienta a etapa que denomina de "transporte" de valores com um exemplo, conforme excerto abaixo.

Professora: É por isso que é bom pegar bem assim primeiro [referindo-se aos cálculos com um algarismo] mas sempre lembrando da unidade, dezena e milhar. Aí quando tem [referindo-se ao número 1 escrito acima do algarismo 1 do cálculo 132 $\times 4$ ] é 0 transporte que a gente fala. Multiplicação por... tu vais transportar 0 um daqui pra casa da centena e somar com a outra centena que já tem lá.

Rosângela: Pedir emprestado para 0 um.

Professora: Não é emprestar, agora é de transportar. [Ênfase na palavra transportar] Rosângela: Aahh, transportar.

Professora: Emprestar é só no de menos, que eu tenho quatro e tenho que tirar seis e aqui tenho dois e um [escrevendo no quadro o cálculo 24 - 16]. De quatro eu não consigo tirar seis, daí eu tenho que pedir emprestado o um pra cá, e aqui vai diminuir um e vai ficar quatorze menos seis [14 - 6]. Aí é um empréstimo.

Professora: Na verdade aqui é um retorno, ele volta pra cá. [Indicando que uma dezena passa a compor 16 unidades]

Rosângela: Se tu pede ele volta né?

Professora: É... 
Figura 3 - Registros no quadro do cálculo efetuado pela professora para mostrar 0 algoritmo da multiplicação e a etapa de transporte.

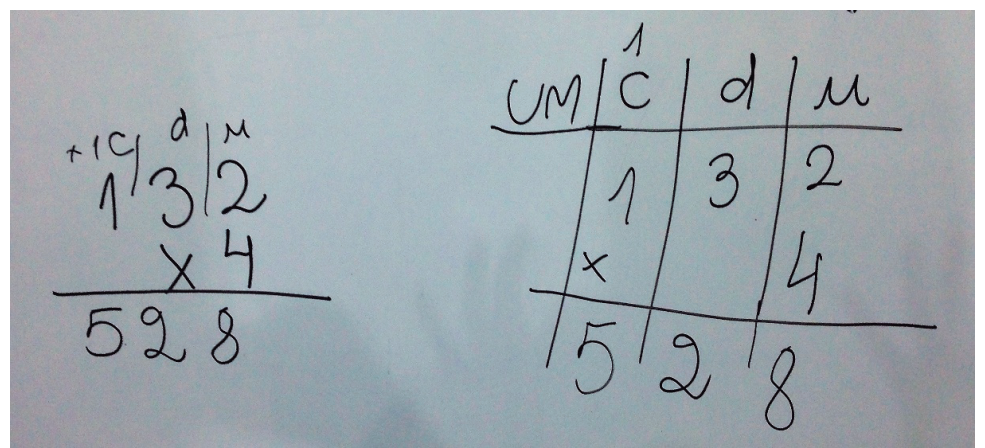

Fonte: Acervo da pesquisadora.

Rosângela pergunta várias vezes se é necessário "pedir emprestado", e a professora enfatiza na sua fala que "não é emprestar, agora é de transportar". Ela mostra um exemplo do que chama de "transporte" e do que denomina "empréstimo". Na multiplicação, não há a etapa de "pedir emprestado", mas ocorre o "transporte" 6 .

Nos dois casos, há uma conversão entre ordens de grandeza: no "empréstimo", uma centena é convertida em 10 dezenas e no "transporte" 10 dezenas são convertidas em 1 centena. Essa conversão havia sido mencionada em aula anterior. Nessa aula, a professora concentra a explicação em distinguir os nomes dados aos procedimentos e em como devem ser executados: as posições dos algarismos devem ser observadas pelos alunos na aplicação do algoritmo. A professora parece considerar que os exemplos são suficientes para esclarecer as diferenças entre os procedimentos nos algoritmos, e encerra 0 assunto.

0 foco da professora com esses dois cálculos, de aplicação dos algoritmos, está na apropriação pelos alunos das regras a serem seguidas na efetivação do cálculo utilizando esse algoritmo: as regras para cada etapa e a ordem correta de execução, seguindo uma sequência ordenada de procedimentos para obter 0 resultado.

Em uma atividade posterior, Alana e Rosângela analisam as suas etapas e procedimentos ao efetuarem 0 cálculo pelo algoritmo. 0 problema era o seguinte: "Uma caixa tem vinte e quatro lápis coloridos. Quatro caixas iguais a esta, quantos lápis têm?"

Antes de resolver, Alana pergunta se "é de vezes também né?". A professora não responde, fala que "é de mais, menos, vezes ou dividir", numa tentativa de que a aluna identifique a operação que deve ser mobilizada para responder o problema. Durante a correção, o erro na aplicação do algoritmo fica visível.

Alana: Professora, deu oitocentos e dezesseis lápis.

Professora: [Lê o enunciado] Vinte e quatro tem em uma caixa, então em quatro vai ter multiplicado por quatro. [Efetua o cálculo]

Rosângela: 0 meu deu oitocentos e dezesseis.

Alana: 0 meu também.

Professora: Oitocentos? Vinte e quatro vezes quatro?

6 Expressão utilizada para indicar a conversão de unidades em dezenas e assim por diante, no algoritmo da adição ou da multiplicação. 
Rosângela: Eu fiz quatro vezes quatro, depois eu fiz duas vezes quatro.

Professora: Tá, por que que deu isso? Porque vocês não estão respeitando o quadrado, a casinha de cada um [desenhando linhas de separação entre as ordens de grandeza das unidades e dezenas]. Tu botaste tudo aqui. Como tu fizeste? [Questiona Rosângela]

Rosângela: Eu fiz aqui quatro vezes quatro deu dezesseis e depois duas vezes quatro dá oito. Mas eu esqueci de fazer isso aí.

Figura 4 - Representação do resultado obtido pelas alunas no cálculo $24 \times 4$.

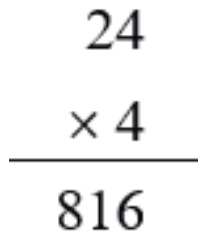

Fonte: Adaptação criada pela pesquisadora para ilustrar a situação narrada.

Para esse problema, Rosângela e Alana encontram o número 816 como resposta. A professora resolveu o problema no quadro utilizando 0 algoritmo e obteve o número 96 como resultado. Para a aplicação do algoritmo, a professora havia orientado que eles poderiam consultar a tabuada que foi fornecida na aula anterior. As alunas copiaram os números que resultaram da tabuada: $4 \times 4=16$ e $2 \times 4=8$. Alana também fala que "encontrou 816" e, para encontrar o erro, a professora busca identificar o que elas fizeram. A professora parece ter identificado que ambas esqueceram do "transporte" da dezena, isto é, não somaram 8 + 1 dezenas como esperado, e explica que elas "não estão respeitando o quadrado, a casinha de cada um", referindo-se à ordem de grandeza dos algarismos. Rosângela argumenta que efetuou a multiplicação, "Eu fiz aqui quatro vezes quatro deu dezesseis e depois duas vezes quatro dá oito". Ela escreveu o resultado dos dois produtos, alinhados, sem considerar que deveria somar $8+1$, sendo ambos algarismos da ordem das dezenas. Ao falar "eu esqueci de fazer isso aí", Rosângela explicita que esqueceu de uma etapa do procedimento.

Professora: Aah, pois é, o dela deu oitocentos e dezesseis. Porquê? Ela não respeitou as casinhas [relacionadas às ordens de grandeza].

Alana: Aah tinha que subir. Eu tava pensando se tinha que fazer isso. "Será que eu subo?" Mas a profe não falou que precisava subir né.

Rosângela: A minha foi errada professora?

Professora: 0 que tu achas: noventa e seis para oitocentos e dezesseis, tem diferença?

Rosângela: Tem.

Professora: Totalmente né. 
Figura 5 - Representação do resultado obtido pela professora no cálculo $24 \times 4$.

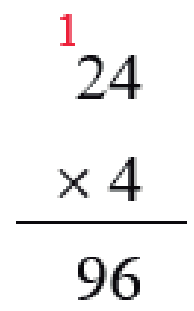

Fonte: Adaptação criada pela pesquisadora para ilustrar a situação narrada.

A professora enfatiza que as posições decimais devem ser respeitadas para a aplicação do algoritmo. Ao refazer o cálculo no quadro, a professora escreve 0 algarismo 1 acima do algarismo 2 das dezenas e Alana percebe que "tinha que subir", mas não tinha certeza do procedimento porque, para ela, a professora não havia deixado explícito que "precisava subir". Alana espera que a professora explicite o procedimento a ser adotado, "tinha que subir", etapa que não foi explicada verbalmente pela professora. A aluna percebeu a necessidade dessa etapa ao observar a resolução do cálculo no quadro pela professora.

A aluna manifesta sua expectativa em relação à orientação dada pela professora, ela espera que a professora indique todas as etapas a serem realizadas, inclusive 0 "transporte". Já a professora, que conhece 0 algoritmo, aguarda que a aluna mobilize um conhecimento já estudado, sobre como considerar as conversões entre ordens de grandeza de um número, para finalizar 0 cálculo corretamente. Isso nos mostra que nem sempre tudo fica claro, explícito em uma negociação. Por parte da aluna e por parte da professora, há uma espera por "algo mais", algo a ser dito, enunciado, escrito, lido, interpretado ou explicado.

Mesmo depois da correção, Rosângela pergunta se "a dela estava errada" e a professora orienta que ela observe a diferença entre os números: 96 e 816. Os alunos têm o hábito de avaliar que números próximos ao resultado correto são "quase" certo. Como a diferença entre os resultados, em termos de quantidade representada, é expressiva, de 96 para 816, ou porque o resultado correto tem dois e não três algarismos, ou talvez porque resulta de um erro na aplicação do algoritmo, a professora salienta que é "totalmente" diferente.

A professora pergunta ao aluno Antônio qual foi a resposta dele, talvez buscando verificar se ele ficou com a mesma dúvida que as alunas quanto ao procedimento de "transporte". Ou, ainda, buscando apoio na resolução correta por outro aluno, para mostrar que eles tinham as informações suficientes para efetuar o cálculo corretamente. A resolução correta é apresentada ou comentada como um modelo a ser seguido.

Professora: Conseguiu? Deu quanto? [Olhando para Antônio]

Antônio: A minha deu noventa e seis.

Professora: Tá. Não pensem assim, "aah tu deu retorno", "não deu retorno"... Deu transporte, "a professora não deu transporte" ou "não falou". Vocês têm que lembrar disso aqui que é importante, da unidade, dezena. Por quê? Têm que lembrar que dezesseis é feito de seis unidades e uma dezena e a casinha das dezenas tá aqui, ela não pode vir direto pra cá. Ela tem que ir para a casinha dela aqui. [Indica no quadro os locais correspondentes às ordens das unidades, dezenas e centenas]. 
Rosângela: Mas mesmo se eu pegar pela tabuada ela vai sair errado igual, professora? Professora: Pode pegar...

Rosângela: Mas ela vai sair... Eu fiz essa pela tabuada. Eu esqueci dessa parte.

Professora: Porque daí tu estás falando de centena, nós não estamos falando de centena ainda. Altera o número total.

Rosângela: É porque saiu três números né?

Professora: Tu tens que botar a dezena na casa da dezena e agora sim tu somas. Tu fizeste a tabuada certa mas tu não respeitaste o quadrado de cada uma. Então, tem que lembrar se o dezesseis é formado de unidade e dezena, ele não pode ficar tudo na casa da unidade. Ele tem que subir. $E$ aí quando ele sobe, eu não vou multiplicar quatro vezes dois vezes um [ $4 \times 2 \times 1]$. É quatro vezes dois mais um. Isso aqui a gente vai entender bem quando a gente fizer na divisão, quando resta a gente soma. Tá, então o que tem que sempre lembrar: 0 quadro de valores.

Seguindo a orientação da professora, Rosângela utiliza a folha com a tabuada, copiando os valores do resultado da multiplicação, $4 \times 4=16$, mas utiliza os dois algarismos do resultado na composição do valor final, sem considerar que era necessário "transportar" uma dezena. Quando ela pergunta "Mas mesmo se eu pegar pela tabuada ela vai sair errado igual professora?", busca a confirmação do procedimento adotado: olhar o resultado da multiplicação na tabuada. Contudo, se fizer isso, "ela vai sair errada", pois Rosângela chegou ao resultado considerado incorreto, mesmo tendo usado a tabuada conforme orientado, pois não lembrou da composição nas ordens de grandeza. Professora e aluna negociam o que fazer e de que modo fazer; 0 que é possível e o que não é possível fazer na operação estudada.

Bishop e Goffree (1986) salientam que

Somente quando ocorre comunicação em que os parceiros querem ouvir e se identificar com o(s) outro(s), esses significados ocultos podem ser explicitados. A comunicação compreendida dessa maneira tem muitas formas - pensar em uma idéia, participar de uma discussão, desempenhar papéis na resolução de problemas, explicar para um colega, defender seu argumento, convencer outros sobre uma afirmação, rejeitar propostas falsas, entrevistar especialistas, fazer perguntas, relatórios, distribuição de tarefas etc. (p. 330, nossa tradução) $)^{7}$

Nesse episódio percebemos que alunas e professora negociam o modo de fazer, argumentam, trazem seus pontos de vista, suas dúvidas, inquietações quanto à explicitação de procedimentos (ou não). As modulações dos discursos nos momentos de negociações caracterizam-se pelo uso alternado de palavras, termos e expressões que são próprias dessa esfera de comunicação. A professora enfatiza as palavras adotadas para caracterizar procedimentos das etapas dos algoritmos, empréstimo e transporte, repetindo e modificando a entonação na pronúncia. Essas palavras associam procedimentos que ela ensinou e ela espera que os alunos também conheçam e entendam suas diferenças. As alunas tentam utilizar as mesmas palavras da professora para as etapas de resolução, buscando associar cada palavra com a ação que deve ser executada. Elas também utilizam palavras que

\footnotetext{
7 No original: "Only when communication occurs in which the partners want to listen to and to identify with the other(s), can these hidden meanings be made explicit. Communication understood in this way has many guises - brainstorming an idea, participating in a discussion, playing roles in problem solving, explaining to a peer, defending your argument, convincing others about a statement, rejecting false proposals, interviewing experts, asking questions, giving reports, distributing tasks etc." (BISHOP; GOFFREE, 1986, p. 330).
} 
correspondem a gestos para caracterizar os procedimentos (como "subir", "voltar"), expressões utilizadas pela professora nas explicações das ações realizadas na aplicação dos algoritmos de cálculo.

Bakhtin (1992) salienta que a comunicação verbal não pode ser compreendida fora do seu contexto de origem, o que nos remete a interpretar as enunciações produzidas na T2 como uma comunicação que ocorre naquele "terreno de produção" e entrelaça-se com enunciados e palavras que só fazem sentido nesse ambiente, com esses interlocutores. Os sujeitos trazem para esse episódio enunciações de outras interações, evocando orientações e regras anteriormente explicitadas, caracterizando o que Bakhtin (1997) considera como a coletividade linguística do enunciado. Assim, as negociações identificadas são características dessa turma, desses alunos e alunas, mas podem nos dar indícios do que acontece em outras turmas, outras salas de aula.

Gomes (2012) salienta a importância de professores da EJA trabalharem com propostas de ensino que propiciem "a (re)construção dos saberes matemáticos por meio da negociação de significados" (p. 64), ligados à realidade dessas pessoas ou que possibilitem conexões com o dia-a-dia deles. Ao olhar para as atividades propostas pela professora, percebemos que elas privilegiam a aplicação do algoritmo focando o procedimento a ser adotado, vislumbrando uma padronização da forma de representação.

Fonseca (2012) alerta para a reprodução de exercícios voltados para 0 ensino de crianças e adolescentes na sala de aula da EJA, desconsiderando a existência de um contato prévio dos alunos com a matemática e, ainda, desconsiderando a faixa etária dos sujeitos e suas vivências. 0 problema das caixas de lápis explora a aplicação do algoritmo. Não há, por parte dos alunos, uma tentativa de conexão com a situação enunciada com a realidade deles; talvez nenhum tenha um conjunto de lápis de cor de 24 cores no seu material escolar e por isso não busquem relacionar o material com o enunciado; ou encaram como um problema de matemática que não precisa necessariamente ter relação com seus cotidianos.

A professora foca na apropriação de estratégias escolares de resolução, tendo em vista um processo de escolarização dos sujeitos. Para os alunos, realizar as atividades envolve o domínio das regras e procedimentos a serem seguidos; tarefas que, sob a perspectiva dos alunos, se revelam bastante complexas.

Observamos que o processo de escolarização envolve muitas negociações, o que nos conduz a concluir que há diferenças de concepções, de pontos de vista e objetivos nessa sala de aula. 0 uso da língua está relacionado com o apropriar-se de práticas daquele contexto, e as negociações de sentidos, presentes a todo o momento, envolvem diferentes modos de se apropriar do conhecimento escolar. Os desafios não são apenas de ordem técnica; há modos específicos de usar a linguagem, formas de se apropriar do conhecimento matemático escolar. As repetições nos mostram que 0 aluno jovem ou adulto nem sempre está pronto ou disposto a se "adequar" ao padrão, à rotina da sala de aula, que abrange um conjunto de rituais e restrições. Essa resistência, quando enunciada, possibilita negociações sobre a sala de aula e sobre a matemática desenvolvida nesse local. Existem muitas regras, operações diferentes, cada uma com procedimentos e etapas específicas, e tudo isso compõe um conjunto complexo de "coisas a aprender" sobre estar na escola, sobre fazer e aprender a matemática escolar.

\section{REFLEXÕES}

A partir das ideias de negociações na sala de aula apresentadas por Bishop e Goffree (1986), propomos olhar para a sala de aula da EJA procurando identificar as negociações que acontecem nesse ambiente e que de algum modo se relacionam com 0 estudo das operações aritméticas 
básicas. Percebemos que o tema das negociações, pouco mobilizado na literatura recente da educação matemática, mantém sua atualidade ao possibilitar um olhar, ou melhor, uma escuta atenta aos sujeitos da sala de aula.

No estudo da multiplicação e do algoritmo escolar, nesta sala de aula, ocorrem negociações envolvendo expectativas, permissões, modulações dos discursos e sentidos atribuídos ao estudo da matemática escolar e à realização das atividades escolares. Os contextos de negociações se apresentam de formas variadas: envolvem as etapas do procedimento, os significados de palavras enunciadas, seguir (ou não) uma orientação dada anteriormente. Esses contextos explicitam o envolvimento dos alunos em um processo de escolarização, em que os alunos são repetidamente solicitados a seguirem as regras e os padrões que são adotados nessa instituição.

As negociações realizam-se privilegiadamente pelas interações verbais, mas também há momentos em que olhares, expressões e silêncios são modos dos sujeitos mobilizarem estratégias para negociar sentidos para o estudo da operação.

As negociações ocorrem porque alunas e professora têm pontos de vista e conhecimentos prévios diferentes. Os sujeitos são singulares, pensam de maneiras diferentes, compreendem/interpretam as enunciações dos outros de modos particulares e estão em constante interação na sala de aula: entre si e com a matemática escolar.

Conforme caracterizado por Fonseca (2007), as interações verbais são uma arena para negociação de significados matemáticos. A negociação entre os sujeitos propicia compreensão, interpretação, análise e descarte (ou aceite) de ideias que possam interferir (ou auxiliar) no estudo da matemática escolar. No episódio em tela, as negociações focalizam a aplicação do algoritmo escolar, de aprendizagem da matemática escolar. As concepções sobre 0 significado da multiplicação são pouco explicitadas e exploradas. A ideia da multiplicação como adição repetida, pela qual a multiplicação havia sido apresentada, poderia ter sido retomada para confrontar as alunas com o resultado encontrado para a multiplicação $24 \times 4$ e incentivá-las a refletir sobre 0 algoritmo utilizado ou até mesmo para a construção e uso de outras estratégias de resolução. Isso não ocorre. Todavia, a verbalização das dúvidas das alunas possibilita identificar 0 erro envolvido na aplicação do algoritmo. A intervenção da professora não se limita a reiterar as orientações para a aplicação correta do algoritmo, mas enfatiza os significados dos diferentes algarismos na escrita dos números buscando a compreensão do sistema de numeração decimal pelas alunas.

Concluímos que negociar em sala de aula envolve explicitar, entender, aceitar ou questionar 0 que é permitido nesse lugar e no estudo das operações aritméticas, e envolve os papeis de professora e alunas na dinâmica da sala de aula e na realização de atividades escolares. Para isso, professora e alunas modulam seus discursos, verbalizam suas expectativas e expõem suas formas de interpretar o conhecimento escolar. Observamos que elas buscam chegar a um acordo, um "meio termo", algo que seja aceito por todas, mesmo que parcial e provisoriamente. 0 contexto pode mudar, mas a negociação continua, não se encerra de forma definitiva. A professora negocia com as alunas visando o estudo da matemática escolar e a apropriação de práticas escolares, envolvendo modos e métodos específicos de efetivação. Ela negocia alguns elementos de linguagem, ouve as exposições e questionamentos das alunas, repete e modifica explicações usando linguagens diferentes, mas impõe 0 uso de determinados procedimentos, modos de fazer e linguagens próprios da matemática escolar. As alunas, por sua vez, escutam as orientações dela, explicitam suas estratégias e dúvidas e questionam os procedimentos orientados por ela ou a ausência de orientação. Há a intenção da apropriação da linguagem escolar, há atenção das alunas e esforço na realização das atividades, mas também há 
resistência e questionamentos sobre os modos de fazer. Elas negociam a validade de suas estratégias, questionam veracidade do modo escolar e testam os limites da dinâmica da sala de aula e da matemática escolar. Ao focar nas negociações, percebemos que o processo de escolarização, de apropriação da matemática escolar, de relacionamento com a instituição escolar, é complexo e peculiar, inclusive para jovens e adultos. A partir disso, conseguimos pensar sobre nossas salas, nossas instituições e práticas escolares. 0 modo como jovens e adultos relacionam-se com a matemática escolar tem sentidos e significados próprios, que merecem ser mais investigados.

\section{REFERÊNCIAS}

BAKHTIN, M. M. Marxismo e filosofia da linguagem. São Paulo: Hucitec, 1992.

BAKHTIN, M. M.. Estética da criação verbal. São Paulo: Martins Fontes, 1997.

BISHOP, A. J.; GOFFREE, F. Classroom organization and dynamics. In: CHRISTIANSEN, B.; HOWSON, A.; OTTE, M. (Eds.). Perspectives on Mathematics Education. Dordrecht: D. Reidel, 1986. p. 309-365.

FONSECA, M. C. F. R. Lembranças da matemática escolar: a constituição dos alunos da EJA como sujeitos da aprendizagem. Educação e Pesquisa, São Paulo. v. 27, n. 2, p. 339-354, 2001.

FONSECA, M. C. F. R. Educação Matemática de Jovens e Adultos: discurso, significação e constituição de sujeitos nas situações de ensino-aprendizagem escolares. In: SOARES, L.; GIOVANETTI, M. A. G. C. (Orgs.); GOMES, N. L. (Org.). Diálogos na Educação de Jovens e Adultos. 2. ed. Belo Horizonte: Autêntica, 2007. p. 225-240. [Primeira edição publicada em 2005]

FONSECA, M. C. F. R. Educação Matemática de Jovens e Adultos: especificidades, desafios e contribuições. 3 ed. Belo Horizonte: Autêntica Editora, 2012. [Primeira edição publicada em 2002]

GOMES, Adriana Aparecida Molina. Aulas investigativas na Educação de Jovens e Adultos (EJA): o movimento de mobilizar-se e apropriar-se de saber(es) matemático(s) e profissional(is). 183p. Dissertação (Mestrado em Educação) Programa de Pós-Graduação Stricto Sensu em Educação, Universidade São Francisco, Itatiba, 2007.

GOMES, A. A. M. Aprender Matemática na Educação de Jovens e Adultos: a arte de sentir e dos sentidos. 354p. Tese (Doutorado em Educação) - Programa de Pós-Graduação em Educação, Universidade Estadual de Campinas, Campinas, 2012.

SANTOS, C. I. C. Inclusão-exclusão nas práticas pedagógicas dos professores que ensinam matemática na educação de jovens e adultos. Dissertação (Mestrado em Educação) - Programa de Pós-Graduação em Educação, Universidade Federal do Rio Grande do Sul, Porto Alegre, 2008.

RECEBIDO EM: 27 abr. 2021

CONCLUÍDO EM: 06 set. 2021 